\title{
Espaço, Totalidade e Método
}

\author{
Space, Totality and Method
}

Rafael Rossi ${ }^{1}$

\author{
Palavras-chave: \\ Ciência \\ Geografia \\ Teoria
}

\section{Keywords:}

Science

Geography

Theory

\begin{abstract}
Resumo
O presente artigo aborda a relação entre espaço geográfico na mediação com a totalidade. Trata-se de uma reflexão de ordem metodológica a partir das contribuições da tradição filosófica conhecida como abordagem ontológica e crítica. Imprescindível, nesta questão, a distinção qualitativa entre a perspectiva gnosiológica e a perspectiva ontológica no processo de produção do conhecimento. Nesse sentido, abordamos, em primeiro lugar, a relação entre teoria, prática e crítica para essa perspectiva em análise, bem como a especificidade do conhecimento científico. Nem a teoria deve subordinar a prática, nem tampouco a prática deve desprezar a teoria. Há uma reciprocidade dialética entre ambas e o conhecimento teórico deve permitir traduzir a essência de movimentos reais e efetivos. Posteriormente demonstramos a função social do espaço geográfico em suas articulações com a totalidade. Concluímos que o espaço geográfico deve ser analisado sempre em articulação com a totalidade e que esta, por sua vez, não pode ser entendida apenas como uma somatória de seus componentes. A totalidade congrega uma rede de mediações qualitativas oriunda das determinações recíprocas que se estabelecem entre os complexos sociais que a constituem e dinamizam. Além disso, apontamos as influências que a produção exerce no espaço pela mediação predominante da totalidade sócio-espacial.
\end{abstract}

${ }^{1}$ Universidade Federal de Mato Grosso do Sul, Campo Grande - MS, Brasil. rafaelrossied@gmail.com 


\section{INTRODUÇÃO}

Este texto é fruto da pesquisa em andamento a respeito da especificidade da particularidade da dimensão educacional e da dimensão geográfica a partir da análise histórica e das contribuições dos autores clássicos destas temáticas. Com o presente artigo, pretendo contribuir, em tom introdutório e aproximativo, com a reflexão entre espaço geográfico, totalidade e método. Mais precisamente: as elaborações da tradição filosófica entendida como perspectiva ontológico-crítica, que remonta desde os gregos até alguns filósofos contemporâneos são significativas para o debate geográfico na questão metodológica, em especial as elaborações de Lukács (1981) e Santos (1988;1997;2007), dentre outros. Não é nosso objetivo demonstrar toda a trajetória do debate entre ontologia e geografia. Este não é o foco deste escrito.

Não estou investindo esforços neste empreendimento, a respeito do espaço, da totalidade e do método; por exercícios academicistas descolados do real. Por outro lado, enquanto pesquisador e professor de geografia, entendo que a compreensão efetivamente crítica da realidade social enquanto totalidade ao longo do processo histórico é um requisito importantíssimo para o entendimento e a intervenção $d o$ espaço.

Nesse aspecto, creio que, em primeiro lugar, cabe explicitar minha compreensão, nesta tradição filosófica já apresentada, da relação entre teoria, prática e crítica e, em segundo lugar, as relações da própria totalidade em seu movimento histórico com o espaço geográfico. Como Aristóteles já alertava: "cada conjunto de princípios devemos investigar da maneira natura e esforçar-nos para expressá-los com precisão [...]" (ARISTÓTELES, 1979, p. 57).

Desse modo, é preciso entender que ontologia diz respeito ao estudo do ser, seja o ser da natureza ou o ser da humanidade, o ser social. Existem ontologias de caráter idealista e ontologias de caráter materialista. Todavia, ponto de vista ontológico indica que "a abordagem de qualquer objeto" deve ter como "eixo o próprio objeto", sendo que "a captura do próprio objeto implica o pressuposto de que ele não se resume aos elementos empíricos, mas também, e principalmente, àqueles que constituem a sua essência". Ou seja: "o elemento central é o objeto" e, com efeito, "não cabe ao sujeito criar - teoricamente - o objeto, mas traduzir, sob a forma de conceitos, a realidade do próprio objeto" (TONET, 2013, p. 14).
Para não haver mal entendidos: quando afirmamos que a centralidade, para a perspectiva ontológica, no processo de conhecimento, está no objeto, de modo algum estamos desprezando as qualidades intelectivas do sujeito que pesquisa. $O$ sujeito, nesta abordagem, deve mobilizar seus conhecimentos científicos, estéticos, filosóficos, históricos e geográficos no sentido de apreender, de traduzir $e$ explicitar o movimento do fenômeno que investiga, inclusive, em suas relações com a totalidade e a particularidade. Em um segundo momento é importante apontar a particularidade da natureza do espaço geográfico em suas infinitas relações com o todo da sociedade, bem como o "momento predominante" nestas interações. Sobre isto trata este texto.

\section{TEORIA E PRÁTICA: LEI E PARTICULARIDADE}

Nosso início de partida na abordagem ontológica: a formação humana, o processo de autoconstrução humana. Por quê? Porque assim ficamos atentos ao movimento da história real e, em articulação com esta, o debate teóricoconceitual. Desse modo, os seres humanos se tornam membros do gênero humano e, portanto, criam a vida em sociedade, quando começam a desempenhar atos de trabalho. Não o trabalho em alguma manifestação concreta de uma determinada sociedade. $\mathrm{O}$ trabalho que permitiu o salto ontológico do ser meramente orgânico ao ser social é o intercâmbio da sociedade com a natureza para a produção dos bens indispensáveis à vida social (se proteger, alimentar etc.). Com o trabalho, de acordo com Lukács (1981), surge um efetivo pôr teleológico, ou seja, uma relação nova entre consciência e realidade.

Para atingir uma determinada finalidade a consciência humana precisa analisar e refletir sobre os elementos naturais do modo como eles são em si mesmos para que aquela determinada necessidade (construir um abrigo, por exemplo) possa ser satisfeita. Com isso, ao final deste processo, foram gerados vários conhecimentos, habilidades, técnicas, ideias e valores que podem ser utilizados em várias outras situações distintas da situação original. Abre-se, assim, a possibilidade de desenvolvimento de novos complexos sociais (educação, geografia, arte, ciência etc.) que terão funções distintas na reprodução social. Cria-se a totalidade e o movimento histórico. Cada vez mais teremos 
sociedades mais complexas, com espaços geográficos mais complexos e individualidades mais desenvolvidas do ponto de vista social. Este processo marca ainda, de modo crescente, a ampliação do domínio humano sobre as forças da natureza que, por sua vez, continuarão com suas próprias legalidades e causalidades, mas, agora, serão constantemente mais conhecidas e sofrerão mais intervenções da atividade sócioespacial humana.

O ser humano passa, enfim, a desenvolver a prática espacial. Uma área natural, terá, crescentemente, mais objetos geográficos e intervenções humanas. Esta é a gênese do espaço geográfico que irá interagir não só com o trabalho, mas com todas as outras dimensões sócio-espaciais. O espaço sofrerá interferência da totalidade, se conformará enquanto todo e, igualmente, exercerá influência na totalidade, já que é um "fator da evolução social, não apenas como uma condição” (SANTOS, 1997, p. 01). O espaço, dessa forma, "contém e é contido pelas demais instâncias, assim como cada uma delas o contém e é por ele contida" (SANTOS, 1997, p. 01). Esta interpretação, de caráter ontológicocrítico, permite entender que "o movimento do espaço, isto é, sua evolução, é ao mesmo tempo um efeito e uma condição do movimento de uma sociedade global” (SANTOS, 1977, p. 89, destaques nossos).

O conhecimento correto (sempre de maneira aproximada e nunca absoluta ou finita) da realidade (seja ela natural ou social) marcará o fundamento elementar do complexo da ciência, de acordo com Lukács (1981). A função da ciência é a intentio recta, isto é, o conhecimento efetivo da realidade em-si-mesma. Trabalho árduo que pressupõe o esforço em desvendar as tendências que se manifestam nos traços de universalidades e nas concreções espaciais em determinados momentos. Aliás, "nada mais fácil que julgar o que tem conteúdo e solidez; apreendê-lo é mais difícil; e o que há de mais difícil é produzir sua exposição, que unifica a ambos" (HEGEL, 1992, p. 23).

$\mathrm{Na}$ relação entre teoria e prática uma não hierarquiza e subordina a outra de modo mecanicista. Nem, tampouco, há uma relação de equivalência igualitária. Poderíamos dizer que a teoria é a reflexão sobre a prática e esta, em seu movimento essencial, é o critério da verdade ou falsidade de uma teoria ou proposição teórica. $\mathrm{O}$ conhecimento teórico "é o conhecimento do objeto - de sua estrutura e dinâmica - tal como ele é em si mesmo, na sua existência real e efetiva, independentemente dos desejos, das aspirações e das representações do pesquisador" (NETTO, 2011, p. 20). A teoria, por isso mesmo, é a "reprodução ideal do movimento real do objeto pelo sujeito que pesquisa", isto é, "pela teoria, o sujeito reproduz em seu pensamento a estrutura e a dinâmica do objeto que pesquisa" sendo que esta reprodução "será tanto mais correta e verdadeira quanto mais fiel o sujeito for ao objeto" (NETTO, 2011, p. 21).

O intelectual, o filósofo, o teórico não são personalidades contemplativas que vivem no mundo das ideias. Alguns até o podem ser. Todavia, a teoria que se mostra mais verdadeira, isto é, aquela que se aproxima mais da totalidade e da essência do objeto, tem um profundo enraizamento na realidade objetiva, na prática social. Não quer dizer que a teoria deva se prender ao fenomênico e ao aparente. Ao contrário: pela teoria científica, há uma ultrapassagem da aparência em suas vinculações de reciprocidade dialética com a essência do objeto. A teoria que apenas explicita o aparente é uma teoria superficial.

Desse modo, o objetivo do pesquisador, "indo além da aparência fenomênica, imediata e empírica - por onde necessariamente se inicia o conhecimento, sendo essa aparência um nível da realidade e, portanto, algo importante e não descartável -, é", em face disto, "apreender a essência (ou seja: a estrutura e a dinâmica) do objeto" e, com a apreensão, sempre aproximativa (já que a realidade é muito mais dinâmica que a teoria), da essência, "o pesquisador reproduz, no plano ideal, a essência do objeto que investigou" (NETTO, 2011, p. 22).

A perspectiva ontológica, dessa maneira, possui como polo central, no processo do conhecimento, o objeto. Parte da constatação de que o objeto é formado por uma reciprocidade dialética entre essência e aparência. Ao mesmo tempo compreende que o objeto possui uma função exclusiva no processo de reprodução da sociedade. Além disso, cada objeto se relaciona com outros objetos e com a própria síntese das relações sociais que é a própria totalidade sócioespacial, historicamente construída e permanentemente em movimento.

É sempre necessário, pois, nesta perspectiva, buscar a origem histórica e ontológica, a natureza e a função social que determinada dimensão desempenha na reprodução da sociedade em articulação com a totalidade e o processo de autoconstrução humana. Daí a importância de compreender que "a ação, que é inerente à função, é condizente com a forma que a contém: assim, os processos apenas ganham inteira significação quando corporificados" (SANTOS, 1997, p. 02). Trata-se do aspecto relacional ao longo do processo histórico na busca pelo entendimento das ações e dos 
conteúdos atuais, pois "o movimento dialético entre forma e conteúdo, a que o espaço, soma dos dois, preside, é, igualmente, o movimento dialético do todo social, apreendido na e através da realidade geográfica” (SANTOS, 1997, p. 02). O espaço, por isso mesmo, "deve ser considerado como uma totalidade, a exemplo da própria sociedade que lhe dá vida" (SANTOS, 1997, p. 05). Deixaremos esta ideia mais clara, no prosseguimento, quando tratarmos do espaço geográfico propriamente dito, todavia, é de extrema importância ponderar que:

O espaço reproduz a totalidade social, na medida em que essas transformações são determinadas por necessidades sociais, econômicas e políticas. Assim, o espaço reproduz-se, ele mesmo, no interior da totalidade, quando evolui em função do modo de produção e de seus momentos sucessivos. Mas o espaço influencia também a evolução de outras estruturas e, por isso, torna-se um componente fundamental da totalidade social e de seus movimentos. (SANTOS, 1977, p. 91)

É nesta relação entre a teoria que busca apreender a essência do objeto que possibilita, inclusive, a elaboração da crítica. A crítica do "conhecimento acumulado consiste em trazer ao exame racional, tornando-os conscientes, os seus fundamentos, os seus condicionamentos e os seus limites - ao mesmo tempo em que se faz a verificação dos conteúdos desse conhecimento a partir dos processos históricos reais" (NETTO, 2011, p. 18).

A crítica, na perspectiva ontológica, será o confronto de uma determinada teoria com o real. É “o real que serve de telão contra o qual é esbatida a teoria" e a teoria "é mostrada como falsa na medida em que ela não é a reprodução fiel do real [...]" (CHASIN, 1988, p. 16). É preciso cuidado aqui. O termo "reprodução fiel" ou o termo "reflexo", no contexto que estamos discutindo, nada tem de simplificador ou parecido com uma cópia fotográfica. Trata-se, em verdade, de uma expressão que busca traduzir tendências reais operantes na objetividade. Uma expressão que precisa buscar a precisão, como Aristóteles (1979) alerta na citação de epígrafe deste artigo. $\mathrm{O}$ movimento, o desenvolvimento, as rupturas e continuidades das essências em aparências constitui o desafio para a atividade científica: "esse movimento das essencialidades puras constitui a natureza da cientificidade em geral. Considerado como conexão do conteúdo delas, é a necessidade e a expansão do mesmo num todo orgânico"
(HEGEL, 1992, p. 39).

Justamente por isso mesmo, na abordagem ontológico-crítica, não há um conjunto de procedimentos analíticos e metodológicos que o pesquisador precisa se munir fortemente para "aplicar" em seu objeto. A ciência "não é precedida por um método, mas começa por ela própria", em outras palavras: "ciência não é aplicar um método, mas é descobrir o segredo do objeto", já que "o que se busca na ciência é a substância, ou seja, se busca aquilo que é o fundamental do ente" (CHASIN, 1988, p. 69). As técnicas de pesquisa: análise documental, filosófica, bibliográficas etc. servirão como meio para o investigador descobrir o movimento real do objeto e não como fim em si mesmas. Em face disto que "uma teoria, isto é, sua explicação, é um sistema construído no espírito, cujas categorias de pensamento reproduzem a estrutura que assegura o encadeamento dos fatos" (SANTOS, 1988, p. 10, destaques nossos).

Chegamos aqui num ponto fundamental: a relação entre lei e particularidade. Para esta tradição que estamos debatendo, as leis gerais dizem respeito aos aprendizados retirados da própria objetividade ao longo do processo histórico. Essas leis gerais, portanto, não rígidas e imutáveis, nem são criações de uma subjetividade que as construiu autonomamente a priori; por outro lado, são expressões teóricas de subjetividades que as traduziram a partir da essência do real. Por exemplo: o processo produtivo, na atualidade, impacta todo o espaço geográfico. Esta é uma lei geral que pode ser constatada amplamente pelas pesquisas. Todavia, a manifestação concreta que as leis se expressam em cada lugar ou em cada território, irá demonstrar a particularização da totalidade, quer dizer: os lugares e os territórios não se explicam por si mesmos, mas em articulação, em suas relações sociais com o espaço geográfico enquanto totalidade entendida não como mero somatório das partes, mas enquanto síntese qualitativa das múltiplas relações que aí se espacializam e se transformam. É necessário, pois, o estudo das interações, pois assim "recuperamos a totalidade social, isto é, o espaço como um todo e, igualmente, a sociedade como um todo. Pois cada ação não constitui um dado independente, mas um resultado do próprio processo social” (SANTOS, 1997, p. 07).

É nesse preciso sentido que "explicar é reencontrar a totalidade" e "compreender, capturar intelectualmente alguma coisa é reproduzir conceitualmente uma unidade que é um todo", pois "cada individualidade no seu isolamento não revela a integridade que ela é”, já que "o todo é que explica" (CHASIN, 1988, p. 
72). A totalidade é esta rede de mediações, esta malha substantiva que interfere na orientação e no rumo de cada complexo social. Ela se apresenta como oriunda de uma construção histórica e como campo de possíveis para desenvolvimentos futuros. Por isso mesmo é dinâmica, mediada, viva... Imbuída de movimento e nunca estática. Isto é: "a totalidade concreta (como suas componentes) é dinamizada através de mediações - uma totalidade imediata é uma totalidade amorfa, inestruturada" (NETTO, 1994, p. 38). Dinâmica que se realiza na história e, com isso, o "valor da variável não é função dela própria, mas do seu papel no interior de um conjunto. Quando este muda de significação, de conteúdo, de regras ou leis, também muda o valor de cada variável" (SANTOS, 1997, p. 11).

Aqui adentramos na consideração do papel de "momento predominante" que a totalidade exerce. Em qualquer relação social, de acordo com Lukács, haverá um momento predominante. Sem este entendimento, caímos num entendimento de totalidade inerte e morta. O momento predominante é "a força das coisas no complexo em que elas estão interligadas" e "complexos integrados pelas mesmas coisas têm momentos de acentuação de predomínio diferente" (CHASIN, 1988, p. 82). Não é uma influência rígida, absoluta ou impermeável, mas sim, enquanto estabelecimento do campo de possibilidades reais e concretas.

O trabalho, por criar a possibilidade do surgimento do ser social, se conforma no momento predominante da origem da totalidade social. Todavia, a totalidade aparece com a "função de mediação indispensável à consubstanciação do ser social" (ANDRADE, 2014, p. 192). Cabe agora esclarecer esta mediação social com o espaço geográfico.

\section{ESPAÇO GEOGRÁFICO: A \\ PARTICULARIDADE E A POSSIBILIDADE}

É fundamental entender a peculiaridade do espaço geográfico. O espaço é sempre "uma realidade relacional: coisas e relações juntas" enquanto "conjunto indissociável de que participam, de um lado, certo arranjo de objetos geográficos, objetos naturais e objetos sociais, e, de outro, a vida que os preenche e os anima [...]" (SANTOS, 1988, p. 10).

Já demonstramos a origem do espaço a partir do salto ontológico ao ser social operado pelo trabalho. Cabe salientar que o espaço não será apenas receptáculo da ação humana. Ao contrário: ele é expressão da multidimensionalidade sócio-espacial ativa e interventiva dos indivíduos em sociedade nas suas mais diversas objetivações e ideações. O "espaço é resultado da ação dos homens sobre o próprio espaço, intermediados pelos objetos, naturais e artificiais" (SANTOS, 1988, p. 25).

O espaço geográfico contemporâneo, fortemente complexo e interligado, faz com que o futuro dos indivíduos se confronte e dependa do futuro do gênero humano. Não mais é possível resolver questões locais apenas operando a partir dos lugares e olhando apenas os territórios em si mesmos. Questões estruturais exigem e demandam soluções globais. Por isso mesmo que "o mundo foi sempre um conjunto de possibilidades. Hoje, porém, tais possibilidades são todas interligadas e interdependentes" (SANTOS, 1988, p. 13).

Apesar do raciocínio do geógrafo brasileiro estar correto na citação anterior, faltou-lhe a apreensão da influência decisiva do momento predominante na relação da totalidade com o espaço geográfico. Isso não é nenhum ataque. Reconheço a importância da sua obra e a concretude de muitas de suas elaborações. Contudo, entendo que não devemos "sacralizar" os autores, mas sim, estabelecer um relacionamento intelectual honesto baseado no cotejamento de suas proposições teóricas com a realidade em sua essência. É verdade que toda totalidade é, ao mesmo tempo, econômica, social, espacial, cultural etc. Todavia, o espaço geográfico apresenta-se enquanto uma totalidade, isto é, um complexo, gerido e orientado por um complexo maior de uma totalidade ainda mais ampla. É justamente por esse motivo que Lukács (2013) entende a sociedade como um "complexo de complexos", ou seja, a interação recíproca e eminentemente dinâmica de várias totalidades em suas distintas funções sociais e particularidades. Santos (1988) acertadamente apreende a existência e importância da totalidade, mas não do momento predominante:

O geógrafo torna-se um empiricista, e está condenado a errar em suas análises, se somente considera o lugar, como se ele tudo explicasse por si mesmo, e não a história das relações, dos objetos sobre os quais se dão as ações humanas, já que objetos e relações mantêm ligações dialéticas, onde o objeto acolhe as relações sociais, e estas impactam os objetos. O geógrafo seria funcionalista se levasse em conta apenas a função; e estruturalista se apenas indicasse 
as estruturas, sem reconhecer o seu movimento histórico ou a relação social sem o conhecimento do que a produziu. Impõese, na análise, apreender objetos e relações como um todo, e só assim estaremos perto de ser holistas, isto é, gente preocupada com a totalidade. (SANTOS, 1988, p. 21)

De fato, concordamos, como já afirmamos no item anterior, com o fato de que os complexos sociais só se fazem plenamente compreendidos em suas vinculações com o todo, incluindo aqui, o espaço geográfico. Inclusive, é preciso notar que "o verdadeiro é o todo. Mas o todo é somente a essência que se implementa através de seu desenvolvimento" (HEGEL, 1992, p. 31). Todavia, cabe ressaltar que mesmo enquanto totalidade, o espaço será orientado a partir das demandas, das possibilidades, das exigências e entraves instaurados pela totalidade na qual se insere enquanto complexo. Este é o sentido da predominância que o momento maior e mais amplo exerce. Para Santos (1988):

O que prejudica é que não conhecemos o fato em si, mas as interpretações que são realizadas pelas agências internacionais. Por isso há necessidade, por parte do intelectual, de ler não apenas uma, mas as várias versões sobre um fato, para que possa ter uma outra visão do mundo, uma visão real dos fatos concretos, já que o mundo pode ser visto com muitas lentes distintas. (SANTOS, 1988, p. 21)

Com efeito, de fato, é imprescindível o conhecimento das distintas posições a respeito dos acontecimentos. Aliás, já Aristóteles afirmava que:

É preciso forçar-nos a ir na direção do extremo contrário, porque chegaremos ao estado intermediário afastando-nos o mais que pudermos do erro, como procedem aqueles que procuram endireitar varas tortas (ARISTÓTELES, 1979, p. 77)

Entretanto, não é simplesmente o confronto entre elas que nos garantirá "uma visão real dos fatos concretos" como apontado pelo geógrafo na citação anterior. É preciso confrontar as divergentes posições e proposições teóricas com a realidade em seu processo histórico, no que apresenta de essencial e este esforço investigativo passa, impreterivelmente, pela apreensão do momento predominante. De fato, no estudo da totalidade é preciso considerar, além das categorias de tempo e escala, as de estrutura, função e forma, já que "a noção de processo permeia todas estas categorias" (SANTOS, 2007, p. 40). Tais categorias são, para o autor, definidoras da "totalidade concreta, a totalidade em seu processo permanente de totalização" (SANTOS, 2007, p. 40). Abre-se a possibilidade da explicação que atingiu a "profundeza da Coisa", isto é: "quando enfim o rigor do conceito tiver penetrado na profundeza da Coisa, então tal conhecimento e apreciação terão na conversa o lugar que lhes corresponde" (HEGEL, 1992, p. 23).

Trata-se de um reconhecimento de ordem ontológica que, apesar de não chamar a atenção para a predominância dos momentos, consegue captar a dinâmica real que se faz presente na dialética totalidade e espaço geográfico. A mediação entre a totalidade e o espaço geográfico se faz, ainda, pela categoria da produção social. Esta é a relevância do médium entre o todo sócio-espacial e o processo históricoespacial. Não apenas a produção no que se refere diretamente ao trabalho e à economia, mas também, a produção da própria vida humana, da vida em sociedade em seus aspectos objetivos e subjetivos:

É evidente que a produção, enquanto momento predominante, é aqui entendida no sentido mais amplo possível - no sentido ontológico -, como produção $e$ reprodução da vida humana, que até mesmo em seus estágios extremamente primitivos (o pastoreio dos mongóis) vai muito além da mera conservação biológica, não podendo portanto deixar de ter um acentuado caráter econômicosocial. É essa forma geral da produção que determina a distribuição no sentido marxiano. Mais exatamente: o que está em jogo aqui são os homens, cujas capacidades, hábitos etc. tornam possíveis determinados modos de produção. Essas capacidades, porém, são por seu turno geradas sobre a base de modos de produção concretos. (LUKÁCS, 2012, p. 336, destaques nossos)

A maneira como os seres humanos, portanto, se organizam na produção social coloca os rumos perante a totalidade sócio-espacial e, com isso, instauram as possibilidades da organização, da distribuição e da produção do espaço geográfico. É preciso sempre ponderar que: "Não se distribui melhor sem mudar a forma de produção, porque a distribuição é produzida pela forma da produção" (CHASIN, 2018, p. 22). Tal influência demonstra o caráter do momento 
predominante nas relações sócio-espaciais.

Desse modo, evidencia-se assim a determinação recíproca entre totalidade e espaço geográfico, exercendo a produção social o papel de momento predominante ao colocar as bases para a distribuição e produção sócioespacial. Esta é uma contribuição de ordem ontológica-crítica que Lukács, por exemplo, pode oferecer à pesquisa e ao ensino de geografia.

\section{CONSIDERAÇÕES FINAIS}

Neste texto apresentamos, em linhas gerais, uma contribuição que a tradição filosófica da perspectiva ontológico-crítica pode oferecer ao entendimento entre espaço geográfico e a sua relação com a totalidade. Em primeiro lugar, trata-se de entender a relação entre teoria, prática e crítica. A teoria, nesta abordagem, se constitui na tradução conceitual de movimentos reais e efetivos em sua essencialidade. A prática, na articulação entre essência e aparência, se configura como contraponto indispensável para a elaboração da crítica ontológica que verifique os avanços, desvios, acertos e lacunas das distintas teorias sociais.

Para a compreensão da gênese da ciência e do espaço geográfico, partimos da constatação, junto com Lukács (1981), de que os indivíduos não nascem já prontos. O ser humano surge na face da Terra no momento em que desenvolve um efetivo pôr teleológico, ou seja, uma articulação nova entre consciência e realidade objetiva que surge, primeiramente e não exclusivamente, a partir dos atos de trabalho, isto é, da transformação teleologicamente orientada da realidade natural para o atendimento de necessidades sociais. Com este processo, abre-se a possibilidade para a origem de novos complexos sociais com funções sociais distintas no processo de reprodução social. Abrese o campo para o surgimento da totalidade, não como uma simples somatória das dimensões que congrega, mas enquanto síntese qualitativa das diversas interações sócio-espaciais.

Nesse aspecto, afirmamos que a totalidade é quem coloca o campo de possibilidades para a orientação do espaço geográfico. Ao mesmo tempo, a própria totalidade ao exercer esse papel de momento predominante, sofre, dialeticamente, interferência do modo como os indivíduos produzem geograficamente a vida em sociedade. A produção social (em sentido amplo), utilizando a totalidade social como mediação, é o momento predominante e, por isso mesmo, detêm a prioridade ontológica na distribuição, organização e produção do espaço geográfico enquanto totalidade. Isto não cancela, contudo, a interferência do próprio espaço no todo social. Este entendimento é um exemplo que abordamos neste escrito a respeito das potencialidades investigativas que a perspectiva ontológica pode oferecer. De certo modo, reafirma o posicionamento de que "a ponte a ser lançada entre possibilidades entreabertas e o ato de construir uma nova história virá do domínio complexo onde se encontram esses mesmos dados, segundo combinações variáveis" (SANTOS, 1988, p. 13). Domínio complexo que virá de nosso conhecimento científico geográfico que consiga traduzir as interações entre totalidade e espaço nos seus momentos predominantes, aliás, "não é difícil ver que nosso tempo é um tempo de nascimento e trânsito para uma nova época” (HEGEL, 1992, p. 26).

\section{REFERÊNCIAS}

ANDRADE, M. A. Trabalho e Totalidade Social: Qual o Momento Predominante da Reprodução Social? In: COSTA, G.; ALCÂNTARA, N. Anuário Lukács. São Paulo: Instituto Lukács, 2014. p. 177-203.

ARISTÓTELES. Ética a Nicômaco. Tradução de Leonel Vallandro e Gerd Bornheim da versão inglesa de W. D. Ross - "Os Pensadores”. São Paulo: Abril Cultural, 1979.

CHASIN, J. Superação do Liberalismo. 1988, mimeografado.

CHASIN, J. Crise Contemporânea e Socialismo Necessário. Revista GESTO-Debate, vol. 11, n. 01, p. 01-23, 2018.

HEGEL, G. W. F. Fenomenologia do Espírito - Parte I. $2^{\mathrm{a}}$ ed. Petrópolis: Vozes, 1992.

LUKÁCS, G. Il Lavoro. In: Per una Ontologia dell'esseresociale.Tradução Mimeo.de Ivo Tonet. Roma: Riuniti, 1981, p. 11-131.

LUKÁCS, G. Para uma ontologia do ser social - I. São Paulo: Boitempo, 2012.

LUKÁCS, G. Para uma ontologia do ser social - II. São Paulo: Boitempo, 2013.

NETTO, J. P. Razão, Ontologia e Práxis. Revista Serviço Social \&Sociedade, n. 44, p. 26-42, 1994.

NETTO, J. P. Introdução ao estudo do método de Marx. São Paulo: Expressão Popular, 2011.

SANTOS, M. Sociedade e Espaço: A Formação Social como Teoria e como Método. Boletim Paulista de Geografia, n. 54, p. 81-100, 1977.

SANTOS, M. Metamorfoses do Espaço 
Habitado - fundamentos Teórico e metodológico da geografia. São Paulo: Hucitec, 1988.

SANTOS, M. Espaço e Método. $4^{\mathrm{a}}$ ed. São Paulo: Nobel, 1997.

SANTOS, M. A Totalidade do Diabo: como as formas geográficas difundem o capital e mudam as estruturas sociais. In: Economia Espacial. São Paulo: Edusp, 2007.

TONET, I. Método Científico - Uma abordagem ontológica. São Paulo: Instituto Lukács, 2013. 